\title{
Study on friction performance and mechanism of slipper pair under different paired materials in high-pressure axial piston pump
}

\author{
Huaichao WU ${ }^{1, *}$, Limei ZHAO ${ }^{1}$, Siliang NI $^{1}$, Yongyong HE $^{2}$ \\ ${ }^{1}$ School of Mechanical Engineering, Guizhou University, Guiyang 550025, China \\ ${ }^{2}$ State Key Laboratory of Tribology, Tsinghua University, Beijing 100084, China \\ Received: 5 December 2018 / Revised: 7 April 2019 / Accepted: 4 July 2019 \\ (C) The author(s) 2019.
}

\begin{abstract}
High-pressure axial piston pumps operate in high-speed and high-pressure environments. The contact state of the slipper against the swashplate can easily change from an oil film lubrication to a mixed oil film/asperity contact, or even dry friction. To improve the dry friction performance of slipper pairs and to avoid their potentially rapid failure, this study examined the effects of material matching on the dry friction performance of the slipper pair for high-pressure axial piston pumps. A FAIAX6 friction and wear tester was developed, and the dry friction coefficients of the slipper pairs matched with different materials were studied using this tester. Based on the thermo-mechanical coupling of the slipper pair with the working process, the contact surface temperatures of the slipper pairs matched with different materials were calculated and analyzed for the same working conditions. Following this, the effects of the material properties on the temperature increase at the slipper sliding contact surfaces were revealed. The reliabilities of the temperature calculations and analysis results were verified through orthogonal tests of slipper pairs matched with different materials. The results indicate that the influence of the material density on the friction coefficient is greater than that of the Poisson's ratio or the elastic modulus, and that the slipper material chosen should have a high thermal conductivity, low density, and low specific heat, whereas the swashplate material should be high in specific heat, density, and thermal conductivity; in addition, the slipper pair should be a type of hard material to match the type of soft material applied; that is, the hardness of the swashplate material should be greater than that of the slipper material.
\end{abstract}

Keywords: axial piston pump; slipper pair; material matching; dry friction; temperature

\section{Introduction}

With the rapid development of the large aircraft industry, the demand for high-pressure axial piston pumps is increasing. The hydraulic systems used in large aircraft are $35 \mathrm{MPa}$ pressure systems, whereas the hydraulic systems of midsized and small aircraft are $21 \mathrm{MPa}$ pressure systems. To improve the reliability of the power supply for large aircraft hydraulic systems, it is necessary to further improve the technical performance of $35 \mathrm{MPa}$ high-pressure axial piston pumps. Slipper pairs are the main force transfer components in such pumps. Compared with other friction pairs of components, slipper pairs are special because they are the direct carrier of the piston cavity pressure, and therefore directly restrict the necessary high speed and high pressure of these pumps. Premature wear of the slipper pairs is one of the main factors affecting the service life of a piston pump [1-3]. Under challenging conditions such as high speed and high

* Corresponding author: Huaichao WU, E-mail: magoubs@sina.com 


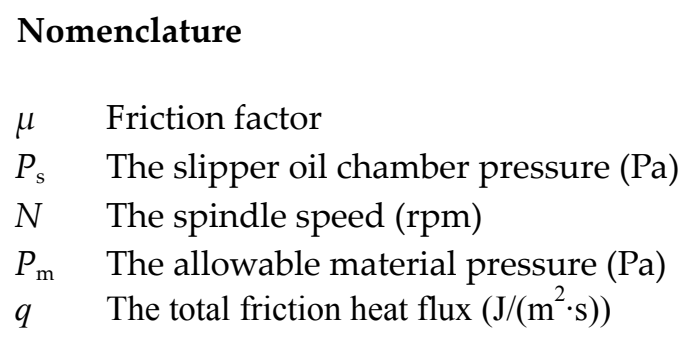

F The axial positive pressure (N)

$v$ The rotational linear velocity $(\mathrm{m} / \mathrm{s})$

ГT The boundary conditions for the entire region

$T_{0} \quad$ The ambient temperature $\left({ }^{\circ} \mathrm{C}\right)$

$\sigma \quad$ Stefan-Boltzmann coefficient (MPa) pressure, the friction state of the contact surface of the slipper pair can easily change from oil-lubricated to mixed or dry friction. The performance of a dry friction surface can be effectively improved by selecting suitably matched materials, and the slipper pair can be prevented from failing too quickly [4]. During a dry friction operation, the frictional heat causes the slipper pair to thermally deform, and the contact pressure on the bearing surface can then increase, directly increasing the heat from friction, leading to hot extrusion deformation on the contact surface of the slipper. Therefore, the dry friction behavior of the slipper pair is the coupled problem of a temperature field and a thermally induced stress field, and the coupling relationship between heat and stress on the friction surfaces is an important basis for the material selection of a slipper pair.

The service life and working performance of axial piston pumps are closely related to the friction pairs [5-8]. Scholars all over the world have carried out numerous studies over the years on the thermal and dry friction characteristics of axial piston pump slipper pairs. The dynamic characteristics of oil films and the energy dissipation of these friction pairs of axial piston pumps were studied by Wieczorek and Ivantysynova [9], and the transient thermoelastic problem involving the viscous friction heat dissipation in an oil film was solved. Considering the thermal effects of oil viscosity, Kazama [10] established a non-isothermal oil clearance model for slipper pairs, the results of which showed that the compression force and the rotation speed of the slippers are the main factors affecting the increase in the oil film temperature. The friction and wear of the friction pairs for axial piston pumps were studied by Canbulut et al. [4], whose results showed that the premature wear of this key friction pair was one of the main causes of the reduced service life of axial piston pumps, and the dry friction performance can be effectively improved by selecting suitably matched materials. To improve the wear resistance of slipper pairs for axial piston pumps, a thermal-structural coupling model of a friction pair, composed of slippers and a swashplate under lubrication conditions, was established by Hashemi et al. [11], who analyzed the heat generation mechanism of the slipper pair. Their results indicate that the slipper boot temperature is mainly affected by the input heat flux and the heat conduction. To date, most studies have focused on the thermal characteristics and friction performance of slipper pairs under oil film lubricating conditions [4, 12]. Although the effects of the physical property parameters of a friction pair on the temperature field of the friction surfaces under dry friction conditions have not been discussed, these parameters have a significant influence on the temperature increase of the friction surfaces and affect the bearing capacity of the slipper pairs.

In this study, the FAIAX6 friction and wear tester was developed. Using this tester, orthogonal experimental studies were carried out on high-pressure axial piston pump slipper pairs with different material combinations under dry friction conditions. The corresponding coefficients of friction for the contact surfaces were calculated and analyzed. Based on the resulting experiment data for the friction coefficients, the dry friction performances of six groups of slipper pairs with different material matches were calculated and analyzed. The temperature distribution of the contact surfaces of the slipper pair were analyzed, and a rule regarding the influence of the material properties on the temperature increase of the contact surface at the bottom of the slipper was revealed. During the experiments, the temperature variation of the contact surface was analyzed, and the rule regarding the influence of the material properties on the temperature increase was verified. This study provides a theoretical basis for the selection of a slipper pair. 


\section{Research and development of a friction performance tester for slipper pairs}

To support the key technology of high-pressure axial piston pumps and enhance the bearing capacity of slipper pairs (avoiding a failure from an accident or use under a state of dry friction), a tester is needed to test the friction performance of the slipper pairs. A FAIAX6 slipper-swashplate friction and wear tester was designed and developed to simulate the working state of the slipper pairs. This tester emulates the experiment conditions needed for a study on the dry friction performance.

A schematic of the tester for the friction performance of slipper pairs is shown in Fig. 1. The tester is mainly composed of a mechanical structure, a hydraulic system, and a control system.

Based on the mechanical structure of the same type of equipment, a clamping device of the upper and lower test specimens was designed for dry friction tests of a slipper pair. Optimizations of the spindle and clamping device of the upper test specimen were carried out, which made their structure more reasonable and increased their matching precision, thereby ensuring the measurement accuracy of the tester. An assembly diagram of the key mechanical components of the tester is shown in Fig. 2. Power is transmitted from the motor, and the motor spindle drives the system rotation through the synchronous belt. The spindle system then drives the rotation of the upper

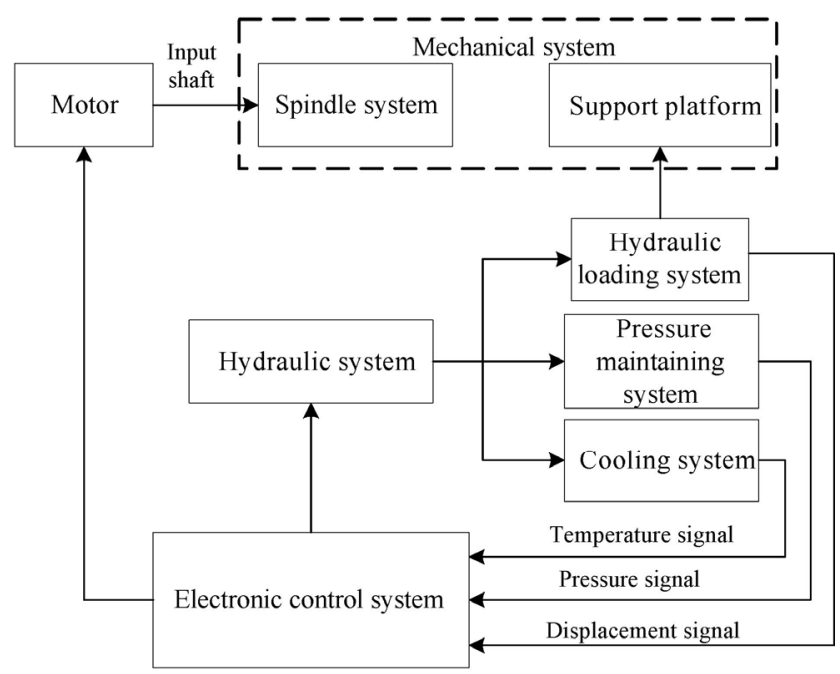

Fig. 1 Block diagram of the tester for friction performance of slipper pairs.

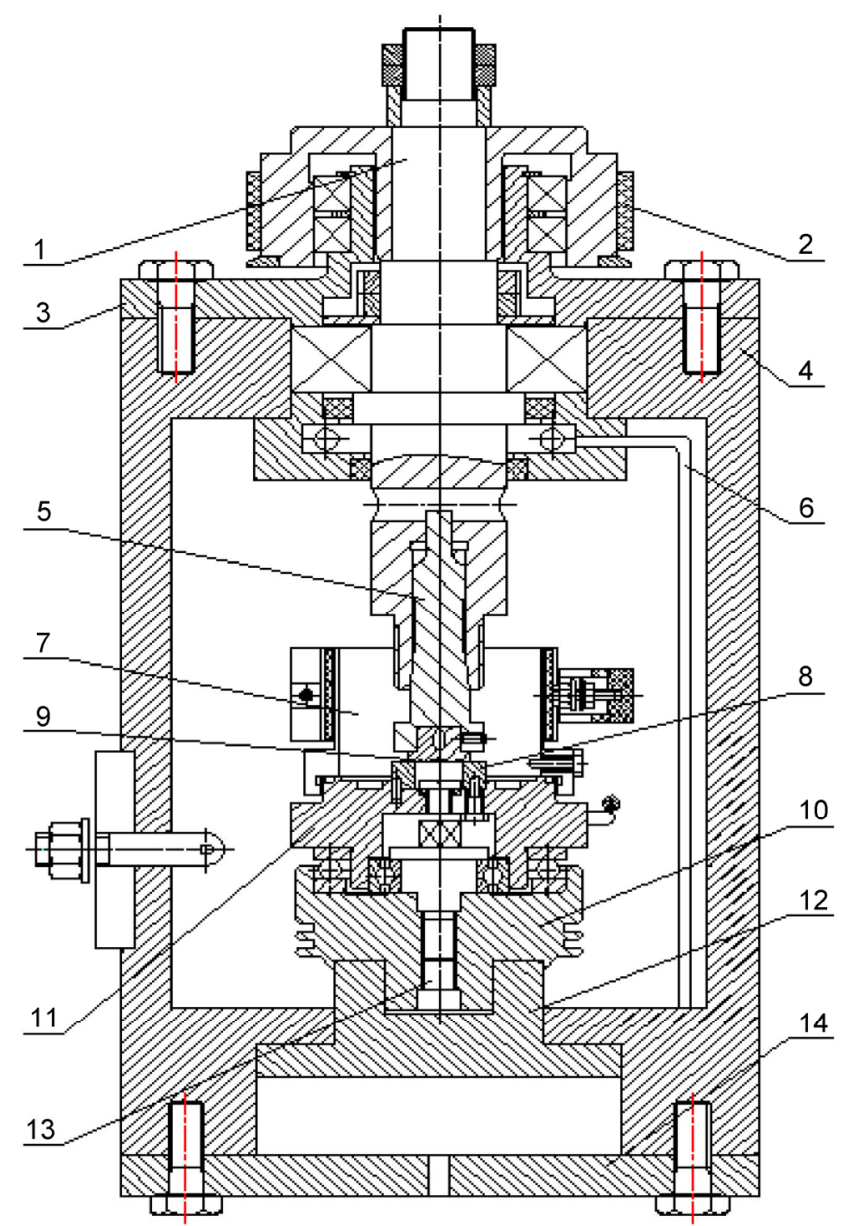

1 Spindle, 2 synchronous belt, 3 upper end cover of the crate, 4 outer case of the crate, 5 clamping device of the upper test specimen, 6 spindle cooling oil circuit, 7 lubricating oil container, 8 lower test specimen, 9 upper test specimen, 10 fixed support platform, 11 rotating support platform, 12 thrust piston, 13 lifting shaft, and 14 lower end cover of the crate

Fig. 2 Assembly drawing showing the key components of the friction and wear tester.

friction pair relative to the lower friction pair.

The hydraulic loading device simulates the load along with the mechanical support platform. During friction performance tests of the slipper pairs, the hydraulic cylinder in the tester should ensure the stable pressure and position accuracy of the hydraulic rod to ensure that the pressure does not decrease, and the position accuracy does not change as the friction force increases. Therefore, the tester uses a closed-loop control system to monitor and modify the hydraulic flow and other parameters in real time. Signals from this control system act on the hydraulic system (Fig. 3) and the motor. The motor and hydraulic system drive the mechanical components. The displacement, 


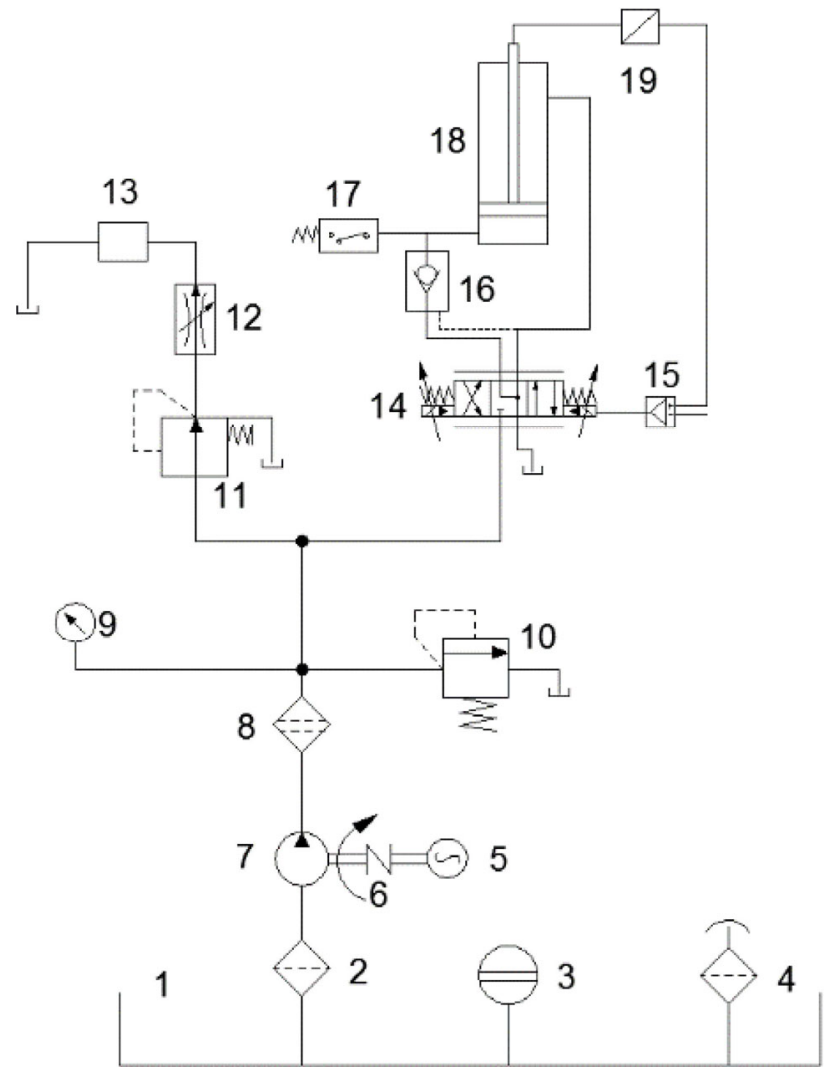

1 Tank, 2 filter, 3 level gauge, 4 air filter, 5 motor, 6 coupling, 7 hydraulic pump, 8 high-pressure filter, 9 pressure gauge, 10 relief valve, 11 relief valve, 12 speed control valve, 13 cooling device, 14 three-position four-way electro-hydraulic proportional reversing valve, 15 amplifier, 16 pilot-controlled check valve, 17 pressure relay, 18 hydraulic cylinder, and 19 displacement sensor

Fig. 3 Hydraulic system principle diagram of the tester.

temperature, and speed signals from the mechanical and hydraulic systems are fed back to the electrical control system. The control system simulates the speed of the slipper pairs under different working conditions by controlling the speed of the servo motor. In this way, the tester is used to test the dry friction performance parameters of the slipper pairs under different speeds and loads through a cooperation of the mechanical, hydraulic, and electrical control systems.

The FAIAX6 slipper-swashplate friction and wear tester, shown in Fig. 4(a), was designed and developed. The loading device of the tester is shown in Fig. 4(b).

\section{Experiment study on dry friction coefficient of slipper pair}

The dry friction coefficient of the contact surface of a slipper pair is one of the important factors in analyzing

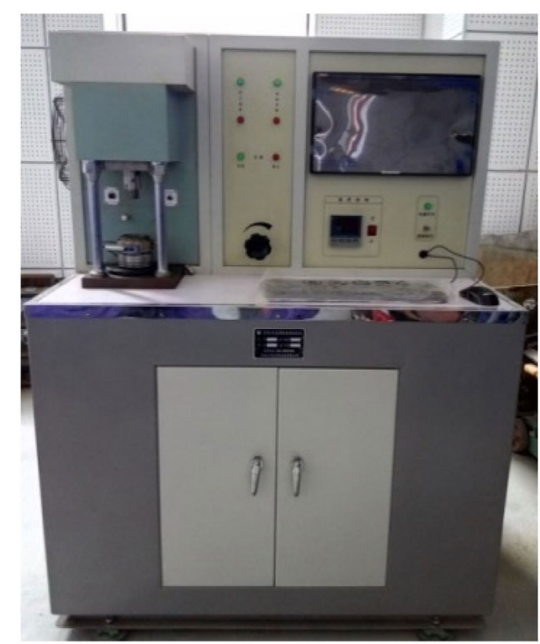

(a) Friction and wear tester.

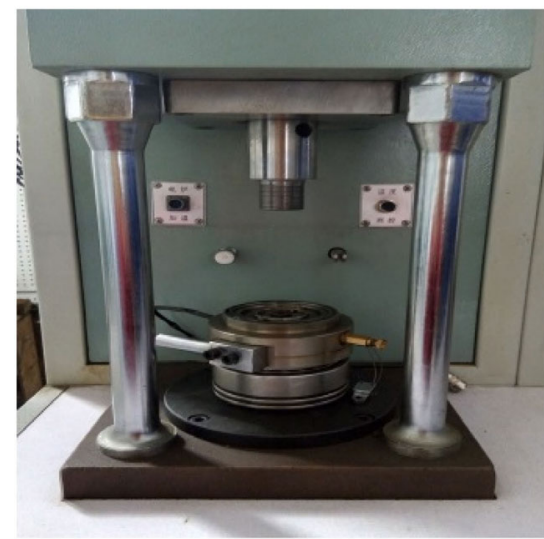

(b) Loading device of the tester.

Fig. 4 High-speed and high-pressure friction and wear tester and its loading device.

the dry friction performance of a slipper pair. At the same time, the dry friction coefficient is also a necessary parameter for the theoretical modeling of the temperature field of a dry friction contact surface.

According to the actual application of the materials of the slipper pair in a high-pressure axial piston pump for civil use, three types of slipper materials (1Cr18Ni9Ti, ZQSn10-1, and ZQAl10-4-4) and two types of swashplate materials (38CrMoAlA and 45 steel) were chosen for the orthogonal experiments on the FAIAX6 friction and wear tester. Because the test specimen was used for dry friction and wear tests, the structure of the slipper diversion groove was simplified for convenient processing, and the sizes of the slipper and swashplate were reduced. The contact surface roughness of all slipper and swashplate test specimens is $0.8 \mu \mathrm{m}$. 
The performance parameters of the selected slipper and swashplate materials are shown in Table 1.

\subsection{Test scheme}

The experiment was carried out using first-order loading. The swashplate test specimen was fixed using a pin and hole assembly as the lower friction pair on the platform. The slipper test specimen was an upper friction pair, fixed to the rotary shaft using a clamping device. At the beginning of the experiment, the upper friction pair remained stationary and the hydraulic system slowly increased the pressure, which made the lower friction pair rise. After the two friction pairs came into contact, the hydraulic system maintained the contact pressure near the set value. The torque measurement device was fixed at this time, and the speed control was applied. Based on the force analysis of the slipper pair, pressure of the contact surface was calculated as $250 \mathrm{~N}$. When the sliding velocity is sufficient, a steady state heat transfer can be reached after a period of time, and the temperature of the entire interface remains unchanged [8]. Therefore, for easier measurements, the test time was set to $30 \mathrm{~s}$, and the experiment speed was set to $400 \mathrm{rpm}$. The data and friction force curves were obtained directly from the output equipment of the tester. The friction coefficient was calculated by measuring the torque of the lower friction pair. The experiment data were recorded once per second for $30 \mathrm{~s}$ for each group under constant pressure.

The matched slipper pairs are shown in Table 2.

\subsection{Experiment results and data analysis}

3.2.1 Analysis of the influence of slipper material on the friction coefficient

The friction coefficients of the three groups (ZQSn101/45 steel, ZQAl10-4-4/45 steel, and 1Cr18Ni9Ti/45 steel) were obtained experimentally, as shown in Fig. 6.

It can be seen from Fig. 6 that the friction coefficients of the contact surfaces increase and fluctuate with time when each material is matched with 45 steel. This is due to the large wear rate of the contact surfaces during the running-in process, and the local wear is intensified by the abrasive dust produced by the friction. This leads to the formation of surface protrusions, and increases friction coefficients. In addition, the bottom surface of the slipper specimen held by the clamping device cannot be accurately held horizontally. According to Fig. 6, the friction coefficient of the ZQSn10-1/45 steel group varied the most smoothly over time, with an average friction coefficient of 0.136 . The average friction coefficient of the ZQAl10-4-4/45 steel group was 0.213 , and the amplitude of the increase was insignificant. The average value of the friction coefficient for the $1 \mathrm{Cr} 18 \mathrm{Ni}$ Ti/ 45 steel group was 0.170 , and the friction coefficient clearly increased over time. The average value of the friction coefficient

Table 1 Material parameters of slipper pair.

\begin{tabular}{|c|c|c|c|c|c|c|}
\hline Alloy & $\begin{array}{l}\text { Density } \\
\left(\mathrm{g} / \mathrm{mm}^{3}\right)\end{array}$ & $\begin{array}{c}\text { Linear expansion } \\
\text { coefficient } \\
\left(10^{-6} / \mathrm{K}^{-1}\right)\end{array}$ & $\begin{array}{l}\text { Thermal } \\
\text { conductivity } \\
(\mathrm{W} /(\mathrm{m} \cdot \mathrm{k}))\end{array}$ & $\begin{array}{l}\text { Specific heat } \\
\left(\mathrm{J} /\left(\mathrm{kg} \cdot{ }^{\circ} \mathrm{C}\right)\right)\end{array}$ & $\begin{array}{l}\text { Poisson's } \\
\text { ratio }\end{array}$ & $\begin{array}{c}\text { Young's modulus } \\
\text { (Gpa) }\end{array}$ \\
\hline $1 \mathrm{Cr} 18 \mathrm{Ni} 9 \mathrm{Ti}$ & 7.92 & 16.7 & 16.1 & 510 & 0.25 & 194 \\
\hline ZQA110-4-4 & 7.5 & 16 & 41.9 & 418.7 & 0.3 & 90.2 \\
\hline ZQSn10-1 & 8.76 & 18.5 & 49 & 396.1 & 0.3 & 102 \\
\hline 38CrMoAlA & 7.86 & 12.3 & 37.67 & 510 & 0.3 & 202 \\
\hline 45 steel & 7.89 & 11.59 & 52.34 & 468 & 0.269 & 209 \\
\hline
\end{tabular}

Table 2 Matching slipper pairs.

\begin{tabular}{cccc} 
Number & A-1 & A-2 & A-3 \\
Slipper material/swashplate material & 1Cr18Ni9Ti/38CrMoAlA & 1Cr18Ni9Ti/45 steel & ZQA110-4-4/38CrMoA1A \\
\hline Number & A-4 & A-5 & A-6 \\
slipper material/swashplate material & ZQAl10-4-4/45 steel & ZQSn10-1/38CrMoAlA & ZQSn10-1/45 steel \\
\hline
\end{tabular}




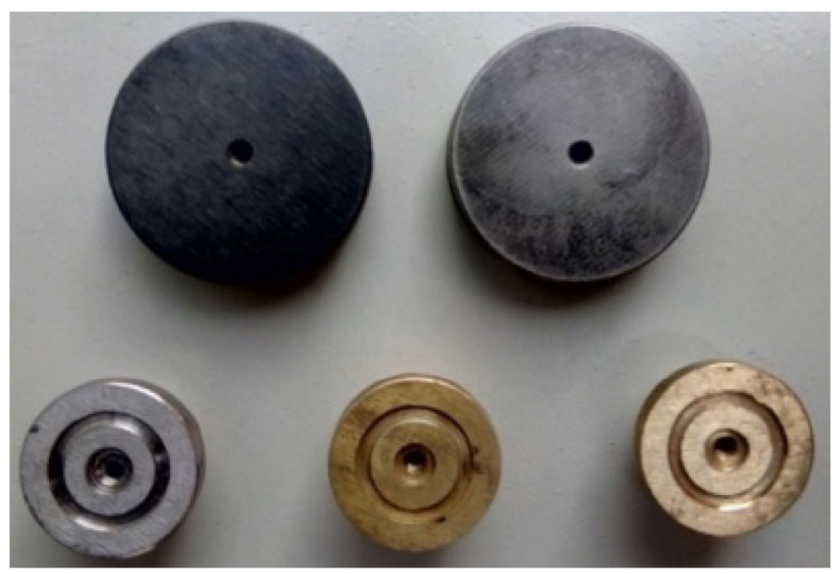

Fig. 5 Photograph of slipper and swashplate test specimens.

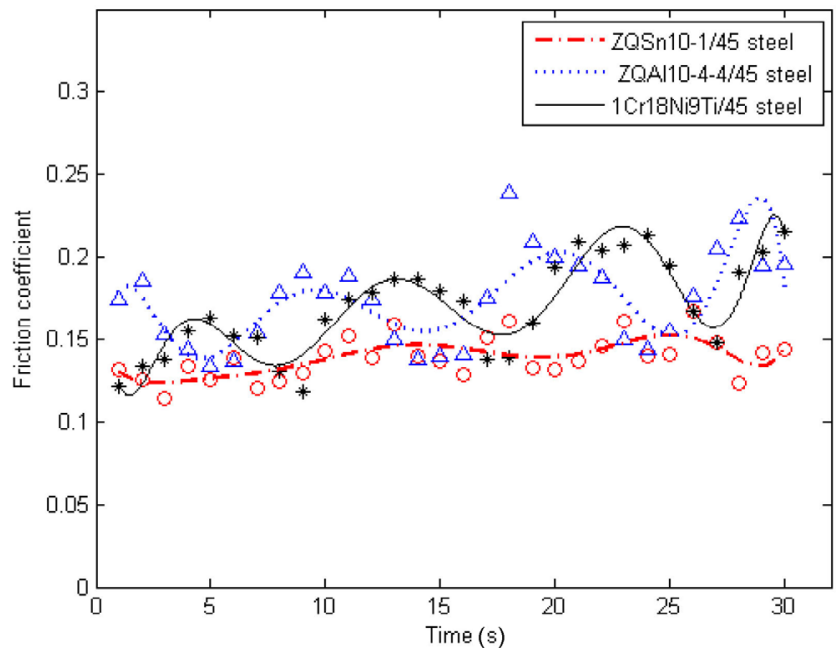

Fig. 6 Variation of friction coefficient on the surface of ZQSn10-1/45 steel, ZQAl10-4-4/45 steel, and 1Cr18Ni9Ti/45 steel.

for ZQSn10-1/45 steel was observed to be the smallest and its variation was the most stable (the best). The $1 \mathrm{Cr} 18 \mathrm{Ni}$ Ti/45 steel group was observed to be the second-best, and the ZQAl10-4-4/45 steel group was the worst. It was found that the density and Poisson's ratio of ZQSn10-1 were both the largest, whereas the elastic modulus was slightly higher than that of ZQAl10-4-4. Although the Poisson's ratio was the same for both ZQAl10-4-4 and ZQSn10-1, the density of ZQAl10-4-4 was the lowest. Therefore, it was concluded that the influence of density on the friction coefficient is greater than that of the Poisson's ratio or elastic modulus. The influence of the materials on the stress distribution of the contact surface of the slipper pair was analyzed earlier, and the results indicate that a good contact stress distribution can be acquired when selecting a slipper material with an appropriate high elasticity modulus, high density, and low Poisson's ratio to match the same swashplate material. Because ZQSn10-1 has the highest density and a slightly higher elastic modulus, the contact stress distribution of the ZQSn10-1/45 steel group is the most uniform, and its friction coefficient is the best. Although the Poisson's ratio of ZQSn10-1 is high, its effect on the stress distribution is relatively small, and thus its effect on the friction coefficient is also small. It is possible that the ZQSn10-1/ 45 steel group has a lower friction coefficient when ZQSn10-1 acts as swashplate material and 45 steel operates as a slipper material, which is contrary to the test scheme described herein.

\subsubsection{Analysis of the influence of the swashplate material on the friction coefficient}

It was found that the ZQSn10-1 contact surface achieved the best performance among the slipper materials tested. Therefore, the influence of the swashplate material on the friction coefficient was analyzed by comparing the matching of ZQSn10-1 with 45 steel and $38 \mathrm{CrMoAlA}$. The variations of the friction coefficient over time for ZQSn10-1/45 steel and the ZQSn10-1/38CrMoAlA groups are shown in Fig. 7.

The friction coefficients for ZQSn10-1/38CrMoAlA and ZQSn10-1/45 steel are shown in Table 3. Compared with the latter, the average and amplitude range of the friction coefficient of the former was observed to be larger. In general, the latter was observed to be better than the former. By comparing the physical properties of the two materials, the density and elastic

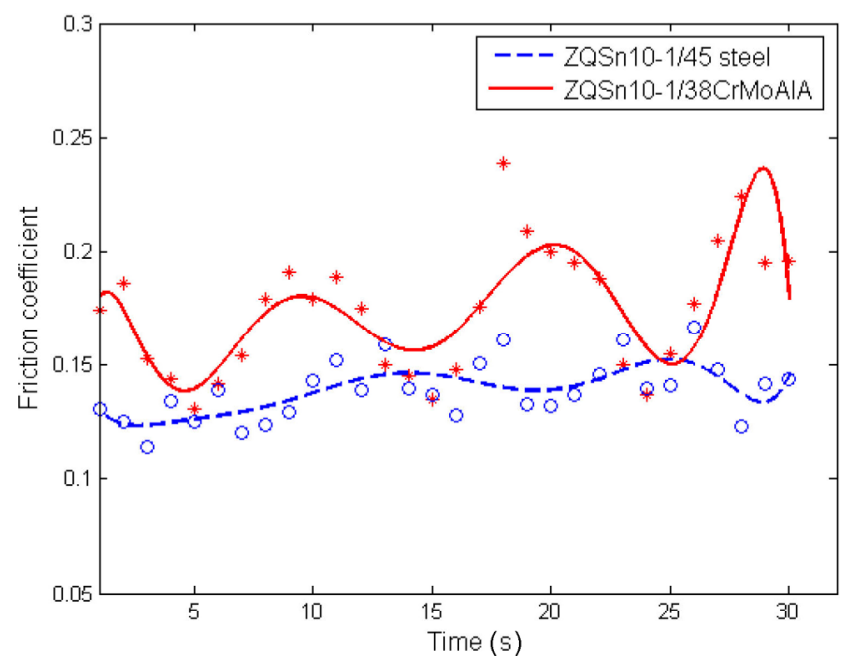

Fig. 7 Variations of the friction coefficient for ZQSn10-1/45 steel and ZQSn10-1/38CrMoAlA. 
Table 3 Friction coefficients for ZQSn10-1/38CrMoAlA and ZQSn10-1/45 steel.

\begin{tabular}{cccc}
\hline Slipper pair & $\begin{array}{c}\text { Average } \\
\text { friction } \\
\text { coefficient }\end{array}$ & $\begin{array}{c}\text { Maximum } \\
\text { friction } \\
\text { coefficient }\end{array}$ & $\begin{array}{c}\text { Minimum } \\
\text { friction } \\
\text { coefficient }\end{array}$ \\
\hline $\begin{array}{c}\text { ZQSn10-1/ } \\
\text { 38CrMoA1A }\end{array}$ & 0.161 & 0.239 & 0.105 \\
$\begin{array}{c}\text { ZQSn10-1/ } \\
\text { 45 steel }\end{array}$ & 0.136 & 0.167 & 0.114 \\
\hline
\end{tabular}

modulus of 38CrMoAlA and 45 steel are similar, and the Poisson's ratio of 38CrMoAlA is slightly higher than that of 45 steel. The reasons for this result were analyzed, and it was found that the two materials have different hardnesses, and the higher hardness of 38CrMoAlA makes the ZQSn10-1/38CrMoAlA group more prone to wear.

\section{Establishment of thermo-mechanical cou- pling calculation model for dry fiction contact surfaces on slipper pairs}

\subsection{Calculation of material characteristics and heat flux}

Temperature and stress fields have a significant influence on the heat dissipation and wear resistance of slipper pairs during an axial piston pump operation. Therefore, the coupling relationship between the temperature and stress fields is an important basis for the structural design and material selection for slipper pairs [13]. During the operation of a high-pressure axial piston pump, its slipper bears a periodic load, thus the friction heat continuously increases, which will worsen the friction and wear properties of the slipper; in addition, the temperature increase will cause a local thermal deformation to occur in the slipper. The force on the bearing surface of the slipper is changed by the thermal deformation. The friction heating is directly related to the contact pressure, and an excessive contact pressure leads to a hot extrusion deformation on the surface of the slipper. This hot extrusion deformation affects the friction state of the contact surface. Therefore, the dry friction behavior of a slipper pair is a coupling problem between a temperature field and a stress field.

Assuming that all friction between the slipper and swashplate is converted into heat, and the input heat flux density of the slipper and swashplate is taken as the boundary condition, the input heat flux equation and the equation used to check the friction surface are as follows $[13,14]$ :

$$
\begin{gathered}
q(x, y, t)=\mu P(x, y, t) v(x, y, t) \\
{[P v]=\pi R_{1}^{2} P_{s} \cdot \frac{2 \pi N R_{1}}{60 \pi\left(R_{1}^{2}-r_{1}^{2}\right)} \leq\left[P_{m} v_{m}\right]}
\end{gathered}
$$

where $q(x, y, t)$ is the input heat flux $\left(\mathrm{J} /\left(\mathrm{m}^{2} \cdot \mathrm{s}\right)\right)$; $t$ is the working time, $p(x, y, t)$ denotes the contact pressure (Pa); $\mu$ is the friction factor, $v(x, y, t)$ denotes the sliding speed $(\mathrm{m} / \mathrm{s}) ; P_{\mathrm{s}}$ is the slipper oil chamber pressure [Pa]; $N$ is the spindle speed (rpm); $R_{1}$ and $r_{1}$ denote the external and inner radii of the slipper, respectively $(\mathrm{mm}) ; P_{\mathrm{m}}$ is the allowable material pressure $(\mathrm{Pa})$; and $v_{\mathrm{m}}$ represents the allowable sliding velocity $(\mathrm{m} / \mathrm{s})$.

If the average temperatures of the contact surface are equal and the heat flux varies continuously, the distribution ratio of the friction heat at the interface is related to the thermal resistance of the two friction surfaces. However, it is difficult to quantitatively determine the thermal resistance between two surfaces in frictional contact. As the boundary condition, the temperature of each pair of contact points must be equal over the real contact area for the slipper pair with the contact friction between the profile peaks. However, outside the real contact area, the surface temperature is not necessarily equal [15]. The boundary condition is expressed as follows:

$$
\left\{\begin{array}{c}
T_{1}^{*}=T_{2}^{*} \\
q_{1}+q_{2}=q
\end{array}\right.
$$

where $T_{1}{ }^{*}$ and $T_{2}{ }^{*}$ represent the characteristic temperatures at the contact areas between the slipper and the swashplate or at the two sides of the contact point $\left({ }^{\circ} \mathrm{C}\right), q_{1}$ and $q_{2}$ are the heat fluxes at the slipper and swashplate contact surfaces $\left(\mathrm{J} /\left(\mathrm{m}^{2} \cdot \mathrm{s}\right)\right)$, and $q$ is the total friction heat flux $\left(\mathrm{J} /\left(\mathrm{m}^{2} \cdot \mathrm{s}\right)\right)$.

The heat generated by the sliding friction between the slipper and swashplate is related to the thermal distribution coefficient $K[16]$ :

$$
K=\frac{q_{1}}{q_{2}}=\frac{\sqrt{\rho_{1} c_{1} \lambda_{1}}}{\sqrt{\rho_{2} c_{2} \lambda_{2}}}
$$


where $\rho_{1}$ and $\rho_{2}$ are the material density $\left(\mathrm{g} / \mathrm{mm}^{3}\right), c_{1}$ and $c_{2}$ are the specific heat $\left(\mathrm{J} /\left(\mathrm{kg} \cdot{ }^{\circ} \mathrm{C}\right)\right)$, and $\lambda_{1}$ and $\lambda_{2}$ denote the thermal conductivities of the slipper and swashplate $(\mathrm{W} /(\mathrm{m} \cdot \mathrm{K}))$, respectively.

The input heat fluxes at the contact surface of the slipper and the swashplate are as follows:

$$
\begin{aligned}
& q_{1}=\frac{K}{1+K} \mu P(x, y, t) v(x, y, t) \\
& q_{2}=\frac{1}{1+K} \mu P(x, y, t) v(x, y, t)
\end{aligned}
$$

For a simplified model of the slipper friction pair, the friction heat at the contact surface can be calculated according to Eqs. (7) and (8):

$$
\begin{gathered}
Q=\mu F v \\
v=\frac{\pi d n}{1000 \times 60}
\end{gathered}
$$

where $\mu$ is the friction coefficient, $F$ is the axial positive pressure $(\mathrm{N}), v$ is the rotational linear velocity $(\mathrm{m} / \mathrm{s})$, $d$ is the average of the external and inner diameters of the contact surface $(\mathrm{m})$, and $n$ is the relative rotation speed (rpm).

\subsection{Temperature field model for slipper pair contact surfaces}

Solving for the temperature field of the slipper pair contact surfaces is a complex problem, which includes the heat conduction in the slipper pair and various boundary conditions. Therefore, a suitable threedimensional transient temperature field model is needed. A differential equation of the three-dimensional transient heat conduction expresses the relationships among the temperature, space, and time, and the temperature distribution of the body can be obtained by solving the differential equation of the heat conduction. The three-dimensional transient heat conduction equation of friction pair can be expressed as follows:

$$
\frac{\rho c}{\lambda} \cdot \frac{\partial T}{\partial t}=\nabla^{2} T_{i}
$$

where $T_{i}$ is the transient temperature of the threedimensional structure of the slipper pair $\left({ }^{\circ} \mathrm{C}\right)$, and $t$ is the time of the rotary friction (s).

During rotary friction, the temperature is constantly changing in the slipper pair. There are frictional heat inputs, and heat dissipation paths such as convective heat loss and radiated heat. The boundary condition of the 3D transient temperature field model is the heat transfer condition for the surface around the temperature field, which reflects the characteristics of the heat exchange process between the contact surfaces of the slipper pair. The boundary conditions for the entire region can be represented by ГT.

$$
\Gamma \mathrm{T}=\Gamma_{1}+\Gamma_{2}+\Gamma_{3}+\Gamma_{4}
$$

where $\Gamma_{1}$ represents the first type of boundary conditions: $T(i, 0)=T_{0}$. Here, $T_{0}$ denotes the ambient temperature $\left({ }^{\circ} \mathrm{C}\right)$. Variable $\Gamma_{2}$ denotes the second type of boundary condition, and $\lambda \partial T / \partial n=q$. Here, $\lambda$ denotes the thermal conductivity of the surface $(\mathrm{W} /(\mathrm{m} \cdot \mathrm{K}))$, and $n$ represents the normal boundary. Variable $\Gamma 3$ denotes the third type of boundary condition, and $\lambda \partial T / \partial n=-h\left(T_{\mathrm{A}}-T_{\mathrm{B}}\right)$. The surface heat transfer coefficient is $h, T_{\mathrm{A}}$ is the temperature of the surrounding medium $\left({ }^{\circ} \mathrm{C}\right)$, and $T_{\mathrm{B}}$ is the temperature of the contact surface $\left({ }^{\circ} \mathrm{C}\right)$. Variable $\Gamma_{4}$ represents the thermal radiation boundary conditions, and $\lambda \partial T / \partial n=\sigma_{\mathrm{A}}\left(T_{14}-T_{24}\right)$, where $\sigma$ is the Stefan-Boltzmann coefficient (MPa), A is the area of the radiating surface $\left(\mathrm{mm}^{2}\right), T_{1}$ is the radiating temperature of the slipper bottom $\left({ }^{\circ} \mathrm{C}\right)$, and $T_{2}$ is the radiating temperature of the upper surface of the swashplate $\left({ }^{\circ} \mathrm{C}\right)$.

\section{Calculation and analysis of the effect of material matching on dry friction surface temperatures of slipper pair}

A simplified thermal-structural coupling model for the dry friction of a slipper pair was established, as shown in Fig. 8. There is normal pressure on the contact surface of the slipper pair. The contact surface rotates around the central axis. The swashplate acts as a static component to support the slipper within the entire system. Therefore, the swashplate was fixed in place, the two axes of the slipper and the swashplate were coincided with each other, and the equivalent stress was applied to the ball head of the slipper. The rotational speed around the axis was applied to the slipper. The slipper was constrained in the other directions. 


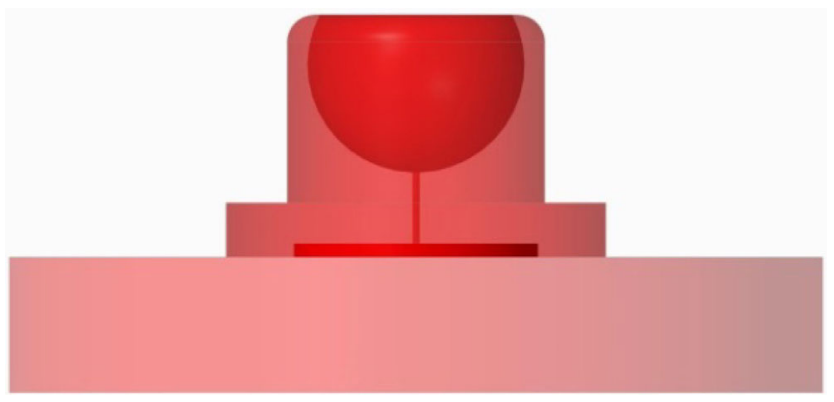

Fig. 8 Simplified model of slipper pair.

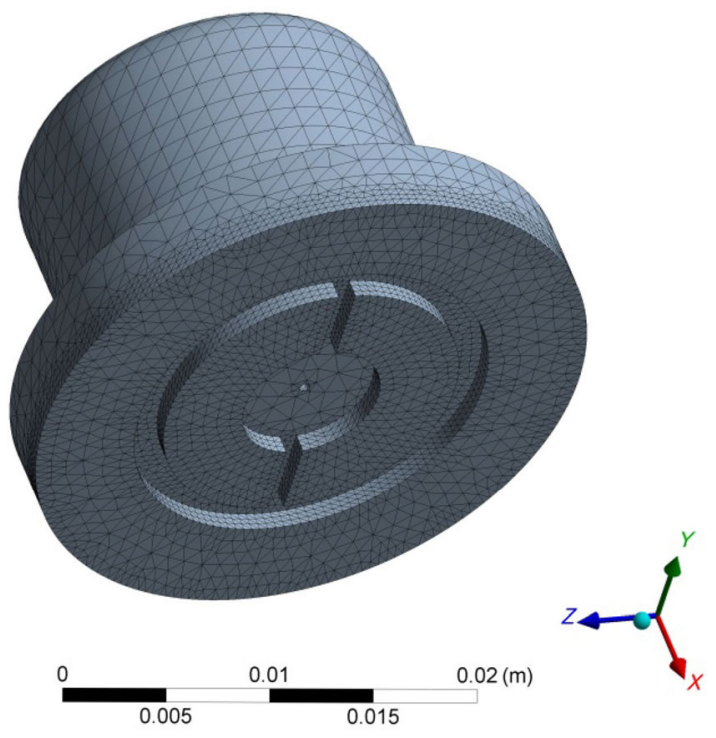

Fig. 9 Slipper mesh division.

Slipper pair matches are shown in Table 2. The dry friction of the slipper contact surface was simulated and analyzed under an oil supply of $35 \mathrm{MPa}$ and a rotational speed of 2,000 rpm.

The temperature distributions at the bottoms of the slippers in A-1, A-3, and A-5 are shown in Fig. 10. According to Fig. 10, the maximum temperature at the bottom of the slippers appeared near the outer diameter of the sealing belt. The highest temperature increase was found in A-1, and the maximum temperatures of all three groups were above $300{ }^{\circ} \mathrm{C}$. If these temperatures are maintained, a rapid wear will occur, leading to a failure of the slipper pair within a short period of time. It was found that the lowest temperature of A-5 was $110.32{ }^{\circ} \mathrm{C}$, and the maximum temperature of $339.27^{\circ} \mathrm{C}$ was lower than that of the other two groups.

The contact surface temperature curves for the A-1, A-3, and A-5 slipper pairs are shown in Fig. 11.

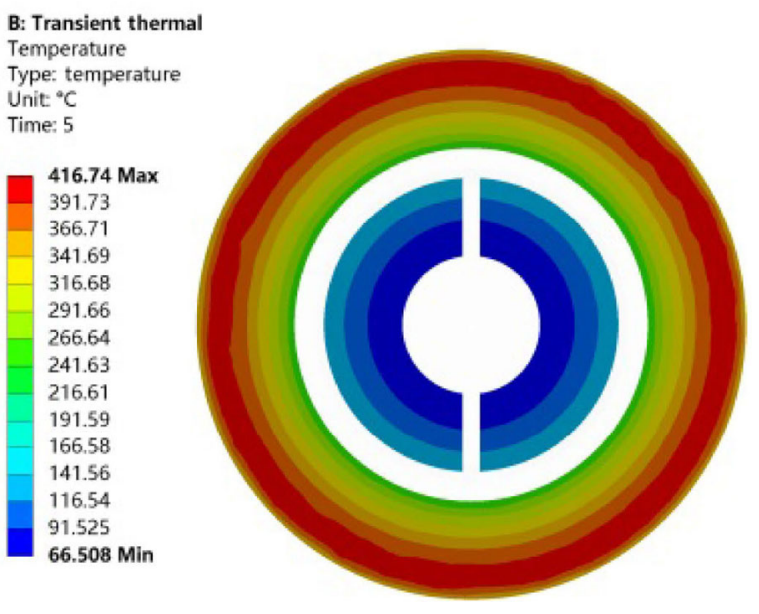

(a) A-1

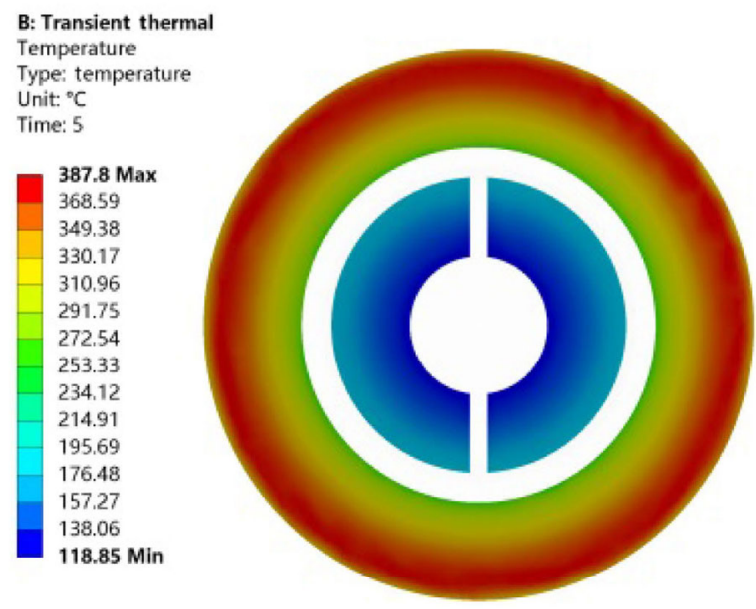

(b) A-3

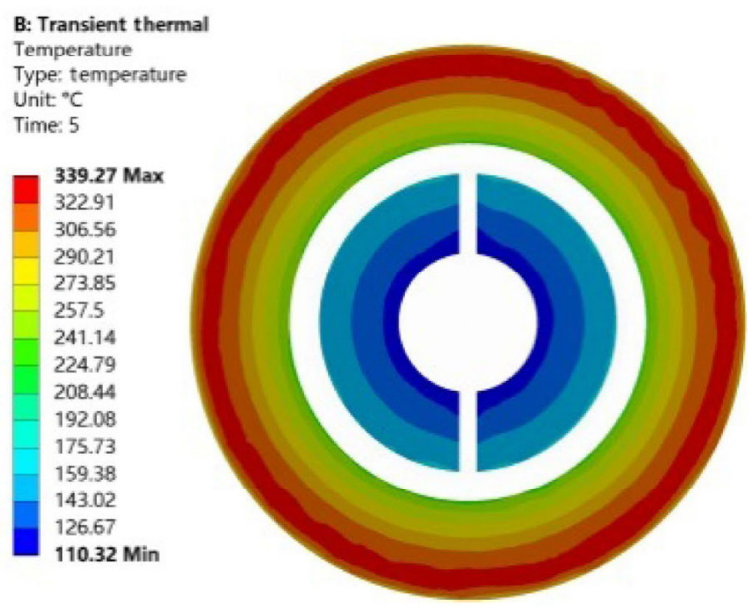

(c) $A-5$

Fig. 10 Temperature distribution at the bottom of slippers matched with 38CrMoAlA. 


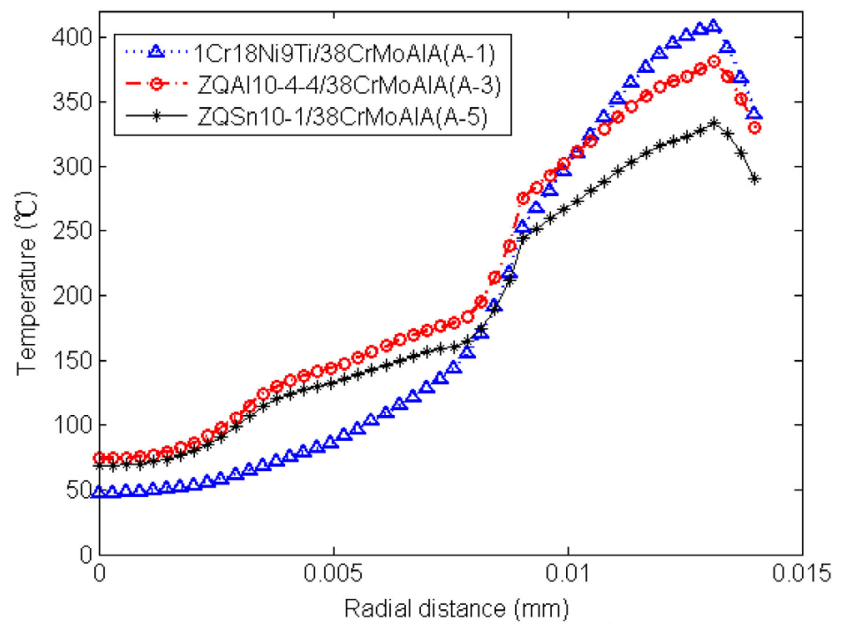

Fig. 11 Temperature curves of contact surfaces.

According to Fig. 11, the maximum temperatures of the A-3 and A-5 contact surfaces were slightly higher than those of A-1 near the center of the contact surface. Far from the center of the contact, the highest temperatures of A-1 and A-3 were observed to be higher than that of $\mathrm{A}-5$, and the highest temperature of A-1 was observed to be the highest in the three groups. The temperature gradient of A-5 was observed to be the smallest. Considering Figs. 10 and 11, it can be concluded that the A-5 pairing was optimal when the friction heat loss caused by a leakage and thermal radiation is ignored, and the heat taken away by grinding is not considered. By comparing the physical parameters of the three types of slipper materials, it was found that the density and thermal conductivity of ZQSn10-1 are the highest, whereas its specific heat was the lowest. The thermal conductivity of $1 \mathrm{Cr} 18 \mathrm{Ni} 9 \mathrm{Ti}$ is the lowest of the three, whereas the specific heat is the largest. The reasons for a good or poor matching were analyzed, and it was determined that, although the specific heat of $1 \mathrm{Cr} 18 \mathrm{Ni} 9 \mathrm{Ti}$ is high and the material can store more heat per unit mass, under high speed and high pressure, the heat produced by dry friction is far greater than the heat absorbed by the material. The temperature of the A-1 contact surface was observed to be the highest because the thermal conductivity of $1 \mathrm{Cr} 18 \mathrm{Ni9Ti}$ is the smallest of the three, and the excess heat cannot be transferred to the outside quickly. Moreover, the thermal conductivity of ZQSn10-1 is the largest; therefore, its thermal distribution coefficient is the largest, and more heat was distributed at the bottom of the slipper. When the temperature difference between the slipper and the surrounding medium gradually increased, a higher thermal conductivity enabled the slipper to dissipate the accumulated heat more quickly, decreasing the contact surface temperature. Thermal conductivity played a decisive role in heat absorption and heat dissipation, and the effect of the thermal conductivity on the heat transfer was greater than that of the specific heat and density under the condition in which the specific heat and density of the two types of slipper materials are similar. Therefore, when matching the slipper pairs, a slipper material with a high thermal conductivity, low density, and low specific heat should be chosen.

The contact surface temperature curves of the A-5 and A-6 slipper pairs are shown in Fig. 12. According to Fig. 12, when the slipper material was invariant, the temperature increase of the contact surface was observed to be higher when the slipper was matched with a swashplate made of 45 steel. Therefore, it can be concluded that $38 \mathrm{CrMoAlA}$ is a better swashplate material than 45 steel. One reason for this is that, although the thermal conductivity of 45 steel is greater than $38 \mathrm{CrMoAlA}$, and the specific heat is less than $38 \mathrm{CrMoAlA}$, the physical properties of 45 steel are more favorable for heat dissipation; however, the contact area between the swashplate and the surrounding media is not large owing to the structural factors of the swashplate, and the accumulated heat at the

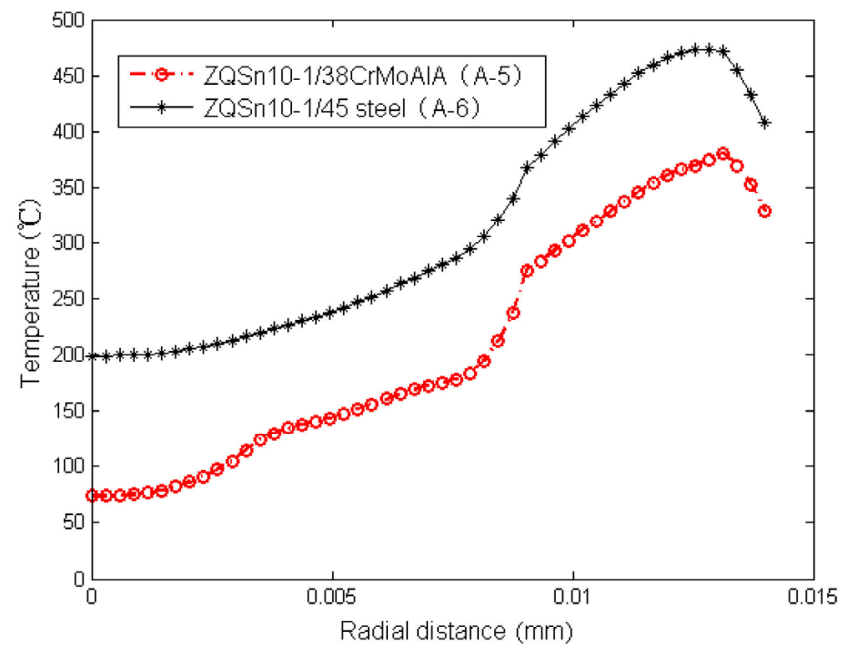

Fig. 12 Temperature curves of contact surfaces with 38CrMoAlA matched with ZQSn10-1. 
contact surface cannot be transferred to the external medium quickly. Therefore, the thermal conductivity of the swashplate material had little effect on the temperature of the contact surfaces. Another important reason is that, at high speed and high pressure, the friction component pairs of ZQSn10-1 and 45 steel are all soft materials, and the increase in the contact surface temperature led to adhesive wear. Most of the energy consumed through a deformation or fracture of the surface material during adhesive wear was converted into frictional heat, which caused the temperature of the friction surfaces to increase. The friction pair of ZQSn10-1 and 38CrMoAlA is a soft-hard pair with a good ability to resist adhesive wear: The amount of friction heat was smaller, and the temperature of the friction surfaces was lower. It can be concluded that slipper pairs should be matched with hard and soft materials, and that the swashplate material should have a high specific heat, density, and high thermal conductivity to reduce the temperature of the contact surface and prolong the service life of the slipper.

\section{Experiment studies on the effect of material matching on the dry friction performance of slipper pairs}

To verify the rules obtained through an analysis described in this paper, the effects of the material matching on the temperature increase of surfaces under dry friction contact were studied experimentally.

\subsection{Experimental scheme}

Slippers of three different materials (1Cr18Ni9Ti, ZQSn10-1, and ZQAl10-4-4) and swashplates of two different materials (38CrMoAlA and 45 steel) were tested using the FAIAX6 friction and wear tester. The loading mode and installation method of the friction pairs were shown to be consistent with those of the dry friction coefficient experiment. The temperature of the room during the experiment was $3{ }^{\circ} \mathrm{C}$. During each experiment, the temperature measurement began when the temperature was reduced to $12{ }^{\circ} \mathrm{C}$, and the experimental data were recorded once per second for $30 \mathrm{~s}$ at a constant pressure.

\subsection{Experiment results and data analysis}

\subsubsection{Analysis of influence of slipper material on temperature}

The curves of the temperature increase of the three slipper pairs (ZQSn10-1/45 steel, ZQAl10-4-4/45 steel, and $1 \mathrm{Cr} 18 \mathrm{Ni} 9 \mathrm{Ti} / 45$ steel) are shown in Fig. 13. As can be seen from Fig. 13, the temperatures of the $1 \mathrm{Cr} 18 \mathrm{Ni9Ti} / 45$ steel group remained constant at $12{ }^{\circ} \mathrm{C}$ during the initial stage, and then increased gradually, and the rate of increase over time was observed to be higher than that of the other two groups. The temperature of the ZQSn10-1/45 steel group was observed to increase earlier than that of the 1Cr18Ni9Ti/45 steel group; however, after $30 \mathrm{~s}$ the temperature of this group was observed to be the lowest among the three groups at $12.6{ }^{\circ} \mathrm{C}$. It can be predicted that if the test length were to be prolonged, the temperature of the $1 \mathrm{Cr} 18 \mathrm{Ni} 9 \mathrm{Ti} / 45$ steel group would be much higher than that of the other two groups, and that the temperature of the ZQSn10-1/45 steel group would be observed to be the lowest of the three groups. Slipper material ZQSn10-1 with a high thermal conductivity is optimal, which agrees with the results of the simulation analysis.

\subsubsection{Analysis of the influence of swashplate material on temperature}

ZQSn10-1 was found to be the best slipper material when comparing the temperature increase of the slipper materials. For this reason, ZQSn10-1 was used as the slipper material to analyze the effect of the swashplate

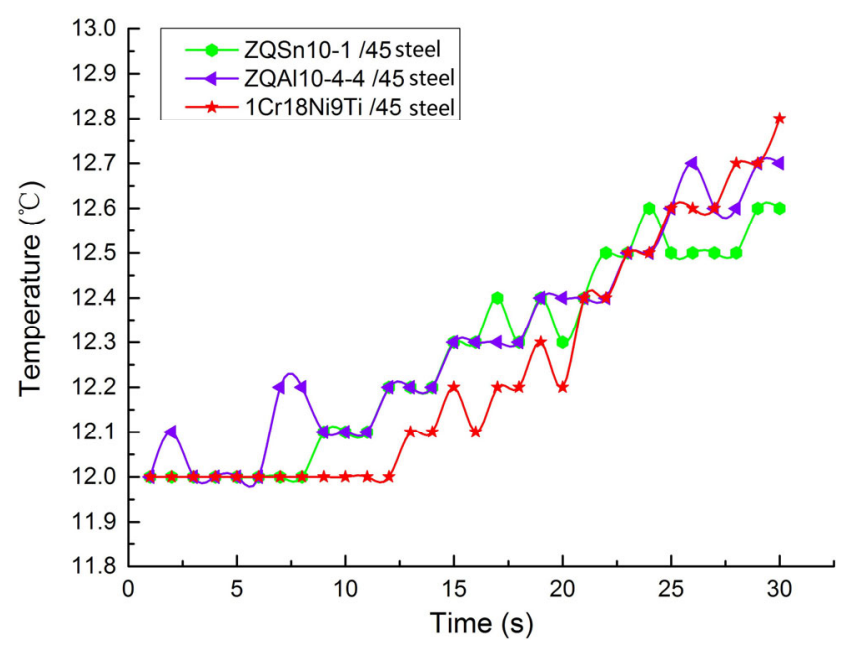

Fig. 13 Temperature increase curves for the three slipper pairs. 


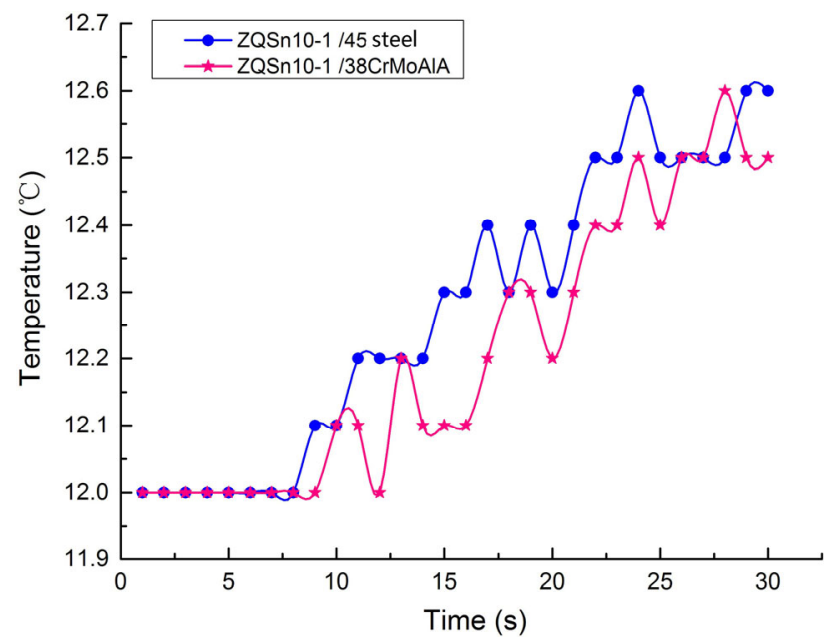

Fig. 14 Curves of temperature increase of ZQSn10-1 matched with 45 steel and 38CrMoAlA.

materials on temperature. The curves showing the temperature increase of ZQSn10-1 matched with those for 45 steel and 38CrMoAlA are shown in Fig. 14. It can be seen that the matching of the ZQSn10-1/ $38 \mathrm{CrMoAlA}$ group with hard and soft materials was slightly better than that of the ZQSn10-1/45 steel group, which is consistent between the results of the calculation and the analysis, verifying the reliability of the results of the temperature field analysis.

\section{Conclusions}

By studying the influence of the physical characteristics of the material on the friction coefficients and temperature increase on the dry friction surfaces of slipper pairs, the following conclusions were drawn.

(1) Regarding the influence of the slipper materials on the friction coefficient, the order of the slipper material from good to bad was ZQSn10-1, 1Cr18Ni9Ti, and ZQAl10-4-4. The influence of density on the friction coefficient was greater than that of the Poisson's ratio or elastic modulus.

(2) The influence of the slipper material on the temperature increase of the contact surface was analyzed, and the order of the slipper materials from good to bad was ZQSn10-1, ZQAl10-4-4, and $1 \mathrm{Cr} 18 \mathrm{Ni}$ Ti. The effect of the thermal conductivity on the heat transfer was greater than that of the specific heat. A slipper material with the highest thermal conductivity, the lowest density, and the lowest specific heat should be selected.
(3) The swashplate material 38CrMoAlA was observed to be better than 45 steel. A slipper pair should be a soft-hard material pair, and the swashplate material with a high specific heat, high density, and high thermal conductivity should be selected to the degree that is most practical.

\section{Acknowledgements}

This project was supported by the National Key Basic Research Program of China (973 Program, 2014CB046404), training plan for high-level innovative talent in Guizhou province (Grant No. Q.K.H.P.T.R.C [2016] 5659), preferred project of scientific and technological activities for personnel studying abroad in Guizhou province (Grant No. Q.R.X.M.Z.Z.H.T [2018] 0001), science and technology planning project in Guizhou Province (Grant No. Q.K.H.P.T.R.C [2017] 5788), and key research project on Innovation group of Guizhou Provincial Education Department (Grant No. Q.J.H. KY Z. [2018] 011).

Open Access This article is licensed under a Creative Commons Attribution 4.0 International License, which permits use, sharing, adaptation, distribution and reproduction in any medium or format, as long as you give appropriate credit to the original author(s) and the source, provide a link to the Creative Commons licence, and indicate if changes were made.

The images or other third party material in this article are included in the article's Creative Commons licence, unless indicated otherwise in a credit line to the material. If material is not included in the article's Creative Commons licence and your intended use is not permitted by statutory regulation or exceeds the permitted use, you will need to obtain permission directly from the copyright holder.

To view a copy of this licence, visit http:// creativecommons.org/licenses/by/4.0/.

\section{References}

[1] Manring N D, Wray C L, Dong Z L. Experimental studies on the performance of slipper bearings within axial-piston pumps. J Tribol 126(3): 511-518 (2004)

[2] Borghi M, Specchia E, Zardin B. Numerical analysis of the dynamic behaviour of axial piston pumps and motors slipper 
bearings. Int J Passeng Cars-Mech Syst 2(1): 1285-1302 (2009)

[3] Pelosi M, Ivantysynova M. A geometric multigrid solver for the piston-cylinder interface of axial piston machines. Tribol Trans 55(2): 163-174 (2012)

[4] Canbulut F, Sinanoğlu C, Koç E. Experimental analysis of frictional power loss of hydrostatic slipper bearings. Ind Lubr Tribol 61(3): 123-131 (2009)

[5] Xu B, Zhang J H, Yang H Y. Investigation on structural optimization of anti-overturning slipper of axial piston pump. Sci China Technol Sci 55(11): 3010-3018 (2012)

[6] Ramesh A, Akram W, Mishra S P, Cannon A H, Polycarpou A A, King W P. Friction characteristics of microtextured surfaces under mixed and hydrodynamic lubrication. Tribol Int 57: 170-176 (2013)

[7] Canbulut F, Koç E, Sinanoğlu C. Design of artificial neural networks for slipper analysis of axial piston pumps. Ind Lubr Tribol 61(2): 67-77 (2009)

[8] Schenk A, Ivantysynova M. A transient thermoelastohydrodynamic lubrication model for the slipper/swashplate in axial piston machines. $J$ Tribol 137(3): 031701 (2015)

[9] Wieczorek U, Ivantysynova M. Computer aided optimization of bearing and sealing gaps in hydrostatic machines-the simulation tool CASPAR. Int J Fluid Power 3(1): 7-20 (2002)

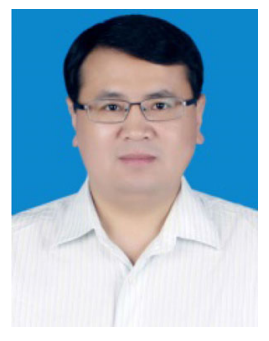

Huaichao WU. He obtained his Ph.D. degree in 2008 from State Key Laboratory of Fluid Transmission and Control, Zhejiang University, China. He carried out postdoctoral research in State key Laboratory of Tribology at Tsinghua University

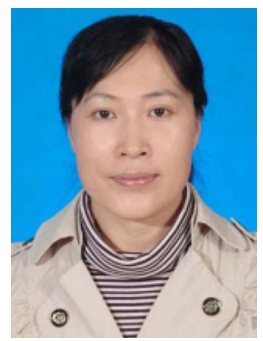

Limei ZHAO. She received the Ph.D. degree in 2013 from Guizhou University, China. She is currently an associate professor and master's
[10] Kazama T. Thermohydrodynamic lubrication model applicable to a slipper of swashplate type axial piston pumps and motors (effects of operating conditions). Tribol Online 5(5): 250-254 (2010)

[11] Hashemi S, Friedrich H, Bobach L, Bartel D. Validation of a thermal elastohydrodynamic multibody dynamics model of the slipper pad by friction force measurement in the axial piston pump. Tribol Int 115: 319-337 (2017)

[12] Rizzo G, Massarotti G P, Bonanno A, Paoluzzi R, Raimondo M, Blosi M, Veronesi F, Caldarelli A, Guarini G. Axial piston pumps slippers with nanocoated surfaces to reduce friction. Int J Fluid Power 16(1): 1-10 (2015)

[13] Abdullah O I, Schlattmann J. Temperature analysis of a pin-on-disc tribology test using experimental and numerical approaches. Friction 4(2): 135-143 (2016)

[14] Pelosi M, Ivantysynova M. Heat transfer and thermal elastic deformation analysis on the piston/cylinder interface of axial piston machines. $J$ Tribol 134(4): 041101 (2012)

[15] Goryacheva I, Makhovskaya Y. Combined effect of surface microgeometry and adhesion in normal and sliding contacts of elastic bodies. Friction 5(3): 339-350 (2017)

[16] Abdullah O I, Schlattmann J. Thermal behavior of friction clutch disc based on uniform pressure and uniform wear assumptions. Friction 4(3): 228-237 (2016)

from 2013 to 2015. He was invited to visit University of California, Davis in USA, in 2016, as a visiting scholar for one year. He is now working as a professor in School of Mechanical Engineering, Guizhou University, China. He has been engaged in the research of friction, lubrication, and electrohydraulic control technology.

supervisor in School of Mechanical Engineering, Guizhou University, China. Her research interests include friction, lubrication, and mechatronic engineering. 